\title{
A standard test for filter media cleanliness
}

\author{
SJ van Staden and J Haarhoff* \\ RAU Water Research Group, PO Box 524, Auckland Park 2006, South Africa
}

\begin{abstract}
Rapid sand filters are expected to produce clean, safe water, without interruption, for many years. Unfortunately, filters very often develop some problems during this time, most of which only become apparent when the damage is already done. Routine measurement of filter media cleanliness could provide the necessary early warning, which is the reason why the American Water Works Association (AWWA) suggested a media cleanliness test for inclusion in a structured filter assessment programme at drinking water treatment plants. After performing such assessments at 3 South African water treatment plants, the authors found that the results were not consistent, the turbidity could not be measured easily and the guideline values seemed to be excessively conservative. This led to an investigation to find a method for stripping the filter deposits from the media grains with an easy, reproducible method, and for characterising the stripped deposits.

After a series of tests on various filter media, using 6 stripping methods, 2 methods were identified that met the criteria in the first objective. The first, a magnetic stirrer method is a mechanical agitation method and the second, referred to as the cylinder inversion method, is a manual agitation method. Each of these methods was chosen on the basis of their operator and speed-ofagitation independence.

The criteria in the second objective were met by an in-depth suspended solids (SS) analysis performed on the filter media residue, with the total mass of solids removed from the media quantitatively separated on the grounds of acid solubility and volatility at $550^{\circ} \mathrm{C}$. Standard Methods (1985) 209C and 209D were applied to the sample, with and without acid addition, in order to characterise the total filter media residue using 4 groupings: Soluble, non-volatile; soluble, volatile; non-soluble, non-volatile; and non-soluble, volatile.

By meeting the criteria of these 2 objectives, the previous non-specific suggestions in the literature have been improved to suggest the performing of tests in a well-specified, uniform way, the results of which can be internally compared.
\end{abstract}

Keywords: filter deposits, filter residue, filter media, cleanliness, floc retention

\section{Introduction}

In almost all South African water treatment plants, rapid sand filtration is the backbone of the process, providing the primary barrier against turbidity and protozoan cysts and oocysts in the final water.

Rapid sand filters almost inevitably develop some technical problems during the many years they are expected to continuously produce clean, safe water. With time, it is observed that media is lost, mudballs are formed, cracks appear, media grains grow by chemical deposition and backwash rates gradually decline due to, e.g. worn pump impellers and leaking valves. Unfortunately, most of these problems become apparent when the damage is already done. However, in all these cases an early warning is given by filter media that are not properly cleaned after every backwash cycle. If the cleanliness of the media grains is routinely measured, the potential for some of the more serious problems could be detected at an early stage and the problem possibly arrested before serious damage is done.

It is such thinking that led the American Water Works Association (AWWA) to include a media cleanliness test (called a floc retention test in their publications) in a battery of tests suggested for a structured filter assessment programme at drinking water treat-

* To whom all correspondence should be addressed.

푱 +2711 489 2148; fax: +2711 489 2148; e-mail: jh@ing.rau.ac.za

Received 30 August 2003; accepted in revised form 10 November 2003. ment plants (AWWA, 2000). The test is simply described as taking approximately $50 \mathrm{~g}$ of filter sand, adding $100 \mathrm{~m} \ell$ of water, shaking it vigorously and decanting the resultant suspension into a beaker. After 5 repetitions, the turbidity of the suspension is measured and reported as NTU (nephelometric turbidity units) / $100 \mathrm{~g}$ of sand. A value of 30 to 60 NTU indicates a clean bed, 60 to 120 NTU indicates a slightly clogged bed, 120 to 300 NTU indicates a clogged filter with mudball formation potential, and values above 300 NTU indicate a serious problem with highly probable mudball formation.

The Water Research Group at the Rand Afrikaans University was involved in such filter assessment programmes at 3 South African water treatment plants during 2000 and 2001 and performed this media cleanliness test with all the other prescribed tests (Ceronio et al., 2002a;b). Some difficulties quickly became apparent. Results were not consistent, the turbidity could not be measured easily and the guideline values seemed to be excessively conservative. The media cleanliness test thus had to be improved and standardised before it could be widely adopted as a comparison standard. The project comprised 2 different parts, which will be reported on in this paper:

- To find a method for stripping the filter deposits from the media grains with an easy, reproducible method, and

- To find a method for characterising the stripped deposits in a meaningful way to provide some clues for corrective action should the media be clogged. 


\section{Experimental work}

\section{Sample and media preparation}

The filter media are sampled according to the needs of the test. If a combined sample through the entire bed is required, a core sampler can be used. If media at a specific depth are required, undisturbed samples have to be taken upon careful excavation of the bed from top to bottom. Because the filter deposits can be surprisingly "patchy", it is always better to sample at 3 or more locations where the same results are anticipated and to make sample composites. The plant from which the media for this investigation was obtained was selected on the basis of the type of raw water treated, i.e. high organic load, high algal mass content and sewage contribution. It is generally known that water of this type would cause media to be "sticky" and difficult to clean. Hence, this choice of media ensures that the methodology would be relevant for all types of treatment plant media.

After sampling, the entire sample has to be homogenised without stripping the filter deposits prematurely from the media grains. For this study, a riffle splitter (such as used in standard engineering soils laboratories) was used to split the sample 5 consecutive times. Thereafter, the sample was sealed in a plastic bag and refrigerated until analysis, which was always done within $5 \mathrm{~d}$ of sampling.

For all the tests described further on, $50 \mathrm{~g}$ of sample was required. To obtain exactly $50 \mathrm{~g}$ of media, small quantities had to be added or taken away a few times, leading to possible disturbance of the filter deposit; a $60 \mathrm{~m} \ell$ measuring cup was used to facilitate this. In this way, a volume of sample could be taken and weighed in one easy step. It was also necessary to take into account the moisture content of the sample. This is done by simply weighing a separate sample of the same media both before and after drying to obtain a mass difference and, thereby, the moisture content (expressed as a percentage) of the sample. After analysis, the final values were mathematically adjusted (taking moisture content into account) to exactly $50 \mathrm{~g}$ of media.

\section{Initial screening of media strip tests}

Three methods were devised with mechanical agitation, which would be operator-independent, namely the shaker table method, the jar test method and the magnetic stirrer method. In view of the fact that not all treatment plants had access to this equipment, 3 further manual agitation tests were devised which could be performed with the absolute minimum of laboratory equipment, namely the hand-swirl method, the cylinder inversion method and the violent shake method. Three different operators repeated these 3 methods, to check for degree of operator dependency. The same media sample was subjected to all 6 tests.

\section{Shaker table method}

Two media samples were placed in $250 \mathrm{~m} \ell$ Erlenmeyer flasks, each with $100 \mathrm{~m} \ell$ tap water. One flask was shaken at $55 \mathrm{U} / \mathrm{min}$ and the other at $200 \mathrm{U} / \mathrm{min}$, using a ROTABIT orbital-swinging shaker, for $30 \mathrm{~s}$. The resultant suspensions were drained off into $2 \times 500 \mathrm{m \ell}$ Erlenmeyer flasks and the procedure was repeated 4 more times, resulting in $2 \times 500 \mathrm{~m} \ell$ suspensions.

\section{Jar test method}

Two media samples were placed in $1000 \mathrm{~m} \ell$ beakers with $100 \mathrm{~m} \ell$ tap water each. One sample was stirred at $30 \mathrm{r} / \mathrm{min}$ and the other at $200 \mathrm{r} / \mathrm{min}$, both using a LEETECH LTS-630III paddle stirrer, for
$30 \mathrm{~s}$. The resultant suspensions were drained off into $2 \times 500 \mathrm{~m} \ell$ Erlenmeyer flasks. The procedure was repeated 4 more times to obtain $2 \times 500 \mathrm{~m} \ell$ suspensions.

\section{Magnetic stirrer method}

Two media samples were placed in $1000 \mathrm{~m} \ell$ beakers with $100 \mathrm{~m} \ell$ tap water each. The samples were then stirred using a HANNA HI $290 \mathrm{~N}$ magnetic stirrer. One sample was stirred at slow speed and one at high speed (these speeds were difficult to define numerically, even though they are measured in rpm units) for 30s. The resultant suspensions were drained off into $2 \times 500 \mathrm{~m} \ell$ Erlenmeyer flasks. The test was repeated 4 more times to obtain $2 \times 500 \mathrm{~m} \ell$ suspensions.

\section{Hand-swirl method}

A media sample was placed in a $500 \mathrm{~m} \ell$ Erlenmeyer flask with $100 \mathrm{~m} \ell$ tap water. The flask was swirled with a gentle wrist turning action for 30s and the resultant suspension drained off into a clean $500 \mathrm{~m} \ell$ Erlenmeyer flask. This procedure was performed 4 times to obtain a single $500 \mathrm{~m} \ell$ suspension for each sample.

\section{Cylinder inversion method}

A media sample was placed in a $250 \mathrm{~m} \ell$ measuring cylinder with $100 \mathrm{~m} \ell$ clean water. The cylinder was sealed at the top and inverted 20 times, as illustrated in Fig. 1 below. After every inversion, the test was momentarily paused to allow the media to settle at the bottom. The resultant suspension was drained off into a $500 \mathrm{ml}$ Erlenmeyer flask. The procedure was repeated 4 more times to obtain a $500 \mathrm{~m} \ell$ suspension.

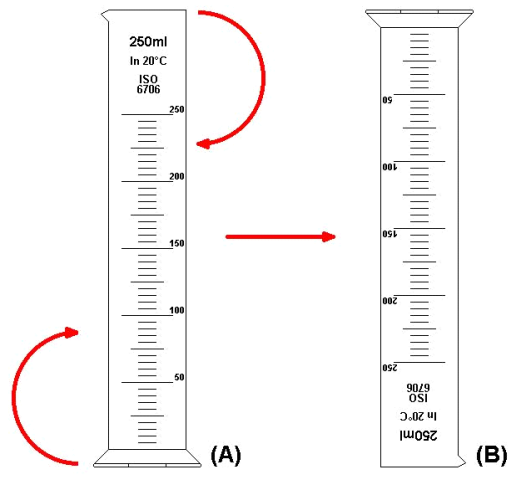

Figure 1

Illustration to show a single inversion of the measuring cylinder, i.e. from position $(A)$ to position $(B)$

\section{Violent shake method}

A media sample was placed in a $500 \mathrm{~m} \ell$ Erlenmeyer flask with 100 $\mathrm{m} \ell$ clean water. The flask was vigorously shaken for $30 \mathrm{~s}$ and the resultant suspension drained off into a clean $500 \mathrm{~m} \ell$ Erlenmeyer flask. The procedure was repeated 4 more times to obtain a single $500 \mathrm{~m} \ell$ suspension.

\section{Turbidity measurement}

Turbidity, measured using a HACH ratio turbidimeter (Model 18900: range 0-200 NTU) and expressed as NTU/100 g media, was the response parameter used to compare the 6 methods. However, the suspension of filter residue in the samples presented 2 problems for turbidity measurement, namely that the relatively large particles caused some "bounce" in the turbidimeter reading, and that the 


\begin{tabular}{|c|c|c|c|c|c|c|}
\hline \multicolumn{7}{|c|}{$\begin{array}{l}\text { TABLE } 1 \\
\begin{array}{c}\text { Single-factor ANOVA results for } 6 \text { methods, testing for the dependence on operator/ } \\
\text { speed, at } \alpha=0.01\end{array}\end{array}$} \\
\hline & & mean & std. & c.o.v. & $F$ value & $F_{\text {crit }} @ \alpha=0.01$ \\
\hline Hand swirl & $\begin{array}{l}\text { Operator A } \\
\text { Operator B } \\
\text { Operator C }\end{array}$ & $\begin{array}{l}66.4 \\
32.7 \\
30.9\end{array}$ & $\begin{array}{l}3.2 \\
2.4 \\
3.5\end{array}$ & $\begin{array}{c}4.8 \\
7.2 \\
11.3\end{array}$ & 429.4 & 5.49 \\
\hline Violent shake & $\begin{array}{l}\text { Operator A } \\
\text { Operator B } \\
\text { Operator C }\end{array}$ & $\begin{array}{l}135.5 \\
640.1 \\
460.8\end{array}$ & $\begin{array}{l}18.6 \\
153.9 \\
167.0\end{array}$ & $\begin{array}{l}13.7 \\
24.0 \\
36.2\end{array}$ & 37.8 & \\
\hline Cylinder inversion & $\begin{array}{l}\text { Operator A } \\
\text { Operator B } \\
\text { Operator C }\end{array}$ & $\begin{array}{l}98.2 \\
105.1 \\
119.6\end{array}$ & $\begin{array}{l}7.6 \\
12.9 \\
11.5\end{array}$ & $\begin{array}{c}7.7 \\
12.2 \\
9.7\end{array}$ & 10.1 & \\
\hline Orbital shaker & $\begin{array}{l}\text { Slow } \\
\text { Fast }\end{array}$ & $\begin{array}{l}43.8 \\
66.4\end{array}$ & $\begin{array}{l}3.7 \\
5.4\end{array}$ & $\begin{array}{l}8.5 \\
8.1\end{array}$ & 118.5 & 8.29 \\
\hline Jar tester & $\begin{array}{l}\text { Slow } \\
\text { Fast }\end{array}$ & $\begin{array}{l}70.2 \\
83.1\end{array}$ & $\begin{array}{c}7.3 \\
13.7\end{array}$ & $\begin{array}{l}10.5 \\
16.5\end{array}$ & 6.9 & \\
\hline Magnetic stirrer & $\begin{array}{l}\text { Slow } \\
\text { Fast }\end{array}$ & $\begin{array}{l}132.4 \\
131.1\end{array}$ & $\begin{array}{l}24.4 \\
13.3\end{array}$ & $\begin{array}{l}18.4 \\
10.1\end{array}$ & 0.022 & \\
\hline
\end{tabular}

suspension settled fairly quickly in the sample cell. Stirring the sample vigorously, then transferring it rapidly into the sample cell and immediately into the turbidimeter overcame these problems.

In addition, the first turbidity reading was taken after $10 \mathrm{~s}$ with consecutive readings every $5 \mathrm{~s}$ up to $30 \mathrm{~s}$, since significant settling a flocculation is not expected to occur over $30 \mathrm{~s}$. The average of these 5 readings is taken as the representative turbidity.

The samples also required dilution before they were within the measuring range of the turbidimeter, therefore requiring the use of a dilution factor, as follows:

$$
\text { Dilution factor }=\frac{\mathrm{m} \ell \text { sample }+\mathrm{m} \ell \text { clean water }}{\mathrm{m} \ell \text { sample }}
$$

Total NTU $=$ measured NTU $\times$ dilution factor

$$
\text { NTU per } 100 \mathrm{~g}=\frac{100 \mathrm{~g}}{\text { mass of media sample }(\mathrm{g})} \times \text { total NTU (3) }
$$

\section{Comparison of results}

For all tests with mechanical agitation, 2 different speeds were selected, and 10 identical samples tested at each speed. For each method, there were therefore $2 \times 10=20$ tests performed. For the tests with manual agitation, 3 different operators each tested 10 identical samples, yielding $3 \times 10=30$ tests for each method. For these initial screening tests, only one response parameter was measured, namely the turbidity of the supernatant, expressed as NTU/100 g of media, which was determined using Eqs. (1) to (3) above (Spaleck, 2001).

Single factor analysis-of-variance (ANOVA) tests were performed for each method and the results are summarised in Table 1.
When comparing the statistical results, the null hypothesis, i.e. the method is operator- or speed-independent, is rejected at the $\alpha=0.01$ level of significance when the $F_{\text {crit }}$ value is larger than the calculated $F$ value. The value for $F_{\text {crit }}$ is read from a table of critical values of the $F$ distribution $\left(F_{0.01}\right)$, using the degrees of freedom, $v_{1}(k-1)$ and $v_{2}(k(n-1))$, where $k$ represents the number of variables tested and $n$ represents the number of tests performed for each variable (Johnson, 1994). Therefore, in terms of mechanical agitation, the jar tester and magnetic stirrer methods showed speed independence, and the magnetic stirrer method was chosen as the favoured mechanical agitation method due to the very low $F$ value for the results. However, none of the manual agitation methods were found to statistically show complete operator independence and, therefore, other generated results need to be compared.

The hand-swirl method was rejected due to the very high $F$ value for the results. The violent shake method was also rejected as it was shown, by plotting the turbidity for consecutive repeats (Fig. 2), that there was a trend for the operator to tire when performing consecutive tests and, therefore, inconsistent results were obtained. Therefore, the cylinder inversion method was chosen as the favoured manual agitation method. In addition, the mean value obtained using the cylinder inversion method is closer to that obtained using the magnetic stirrer method.

The two favoured methods were then subjected to further testing and refinement in the next section.

\section{Refinement of the cylinder inversion method}

Three experimental variables in this method were changed, resulting in 7 tests being devised. The variables tested were the number of inversions, the size of the cylinder and the ratio of the number of inversions to the number of washes. The same media sample was subjected to all 7 tests. 


\begin{tabular}{|c|c|c|c|c|c|c|}
\hline \multicolumn{7}{|c|}{$\begin{array}{c}\text { TABLE } 2 \\
\text { Single-factor ANOVA results for } 7 \text { cylinder inversion methodologies }\end{array}$} \\
\hline & & Mean & $\begin{array}{c}\text { Std. } \\
\text { deviation }\end{array}$ & c.o.v. & $F$ value & $\begin{array}{c}F_{\text {crit }} @ \\
\mathrm{a}=0.01\end{array}$ \\
\hline No. of inversions & $\begin{array}{l}10 \\
20 \\
40\end{array}$ & $\begin{array}{l}597.0 \\
774.0 \\
790.7\end{array}$ & $\begin{array}{c}161.1 \\
32.0 \\
74.9\end{array}$ & $\begin{array}{c}27.0 \\
4.1 \\
9.5\end{array}$ & 3.2 & 10.92 \\
\hline Cylinder size & $\begin{array}{l}250 \mathrm{~m} \ell \\
500 \mathrm{~m} \ell\end{array}$ & $\begin{array}{l}755.0 \\
876.3\end{array}$ & $\begin{array}{c}16.0 \\
104.7\end{array}$ & $\begin{array}{c}2.1 \\
11.9\end{array}$ & 3.9 & 21.18 \\
\hline Inversion:wash ratio & $\begin{array}{l}20: 5 \\
50: 2\end{array}$ & $\begin{array}{l}787.3 \\
786.7\end{array}$ & $\begin{array}{l}56.6 \\
52.5\end{array}$ & $\begin{array}{l}7.2 \\
6.7\end{array}$ & 0.00022 & \\
\hline
\end{tabular}

Comparison of cylinder inversion method results

For the first variable tested, i.e. the number of inversions, 3 identical samples were tested for each number of inversions. Therefore, there were $3 \times 3=9$ tests for this variable. For the second and third variables tested, i.e. the size of the measuring cylinder and the ratio of the number of inversions to number of washes, 2 different sizes and ratios were used respectively and 3 identical samples were tested for each. Therefore, there were $2 \times 3=6$ tests for each of these 2 variables.

$\underline{\text { Violent shake method turbidities }}$

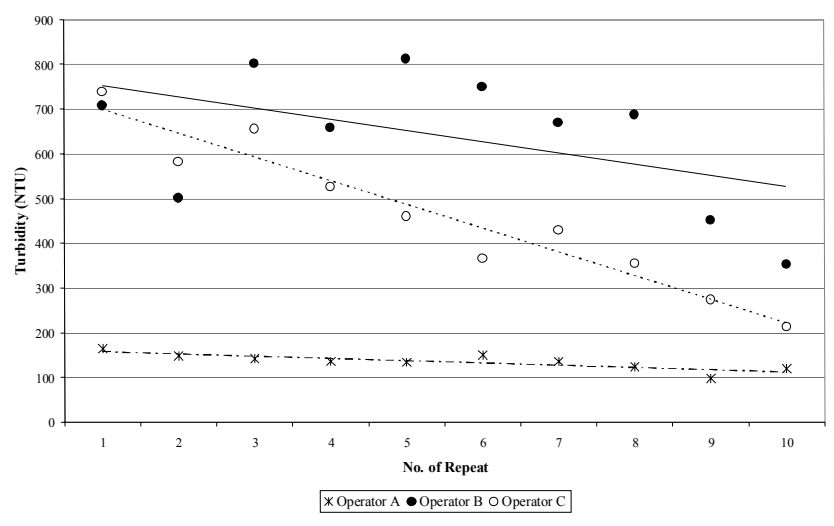

Figure 2

Violent shake method turbidity results for 3 operators, plotted with trendlines. This illustrates that the turbidity decreases over consecutive tests and, therefore, that the operators tire.

\section{Number of inversions}

Three media samples were placed in $250 \mathrm{~m} \ell$ measuring cylinders, each with $100 \mathrm{~m} \ell$ tap water. One flask was inverted 10 times, the second 20 times, and the third 40 times. The resultant suspensions were drained off into $3 \times 500 \mathrm{~m} \ell$ Erlenmeyer flasks and the procedure was repeated 4 more times, resulting in $3 \times 500 \mathrm{m \ell}$ suspensions.

\section{Size of the measuring cylinder}

One media sample was placed in a $250 \mathrm{~m} \ell$ measuring cylinder, and a second media sample was placed in a $500 \mathrm{~m} \ell$ measuring cylinder, each with $100 \mathrm{~m} \ell$ tap water. Each sample was inverted 20 times and the resultant suspensions drained off into $2 \times 500 \mathrm{~m} \ell$ Erlenmeyer flasks. The procedure was repeated 4 more times to obtain $2 \times 500$ $\mathrm{m} \ell$ suspensions.

\section{Ratio of number of inversions to number of washes}

Two media samples were placed in $500 \mathrm{~m} \ell$ measuring cylinders with $100 \mathrm{~m} \ell$ tap water each. One sample was inverted 20 times and the other 50 times. The resultant suspensions were drained off into $2 \times 500 \mathrm{~m} \ell$ Erlenmeyer flasks. The test was repeated 4 times for the sample that was inverted 20 times and once more for the sample that was inverted 50 times, resulting in $1 \times 500 \mathrm{~m} \ell$ suspension and $1 \times 200 \mathrm{~m} \ell$ suspension respectively.
Single-factor ANOVA tests were performed for each method, with the null hypothesis stating that there is no difference in the results due to a change in the variables. The results of these analyses are summarised in Table 2.

The results for all 3 tests were found to comply with the null hypothesis and, therefore, comparisons of the coefficient of variation (c.o.v.) results were performed to choose which method was favoured.

The c.o.v. value for the 20 inversions was found to be considerably lower than the other 2 values (just under half of that of the 40 inversions, with the 10 inversions value nearly 7 times greater). It was, therefore, concluded that 20 inversions of the measuring cylinder should be used for the final method.

The c.o.v. value for the $500 \mathrm{~m} \ell$ measuring cylinder was found to be almost 6 times that of the $250 \mathrm{~m} \ell$ measuring cylinder and, therefore, the $250 \mathrm{~m} \ell$ measuring cylinder was selected for use in the final method.

Both the c.o.v. values for the inversion:wash ratio methods were approximately 7 and, therefore, further analysis was necessary. After further consideration, it was concluded that a $500 \mathrm{~m} \ell$ supernatant would prove to be better, since a dilution factor for a $200 \mathrm{~m} \ell$ supernatant would be greater than that for a $500 \mathrm{~m} \ell$ supernatant and, therefore, may result in less reliable results.

Therefore, the optimal cylinder inversion method would make use of a $250 \mathrm{~m} \ell$ measuring cylinder, with the sample inverted 20 times and a total of $500 \mathrm{~m} \ell$ supernatant being produced, i.e. the sample would be washed 5 times.

\section{Refinement of the magnetic stirrer method}

Four experimental variables in this method were changed, resulting in 8 tests being devised. The variables tested were the size of the beaker, the stirring speed, the stirring duration and the size of the magnetic stirrer. The same media sample was subjected to all 8 tests.

\section{Size of the beaker}

One media sample was placed in a $250 \mathrm{~m} \ell$ beaker (internal diam. $65 \mathrm{~mm}$ ) and a second in a $500 \mathrm{~m} \ell$ beaker (internal diam. $75 \mathrm{~mm}$ ), each with $100 \mathrm{~m} \ell$ tap water. Each sample was stirred at high speed for $60 \mathrm{~s}$ using a large magnetic stirrer (see Fig. 3 below). The resultant suspensions were drained off into $2 \times 500 \mathrm{~m} \ell$ Erlenmeyer flasks and the procedure was repeated 4 more times, resulting in 2 $\times 500 \mathrm{~m} \ell$ suspensions. 
Stirring speed

Two media samples were placed in $250 \mathrm{~m} \ell$ beakers, each with $100 \mathrm{~m} \ell$ tap water. One sample was stirred at slow speed and the other at high speed, both for $60 \mathrm{~s}$, using a large magnetic stirrer (Fig. 3 below). The resultant suspensions were drained off into $2 \times 500 \mathrm{~m} \ell$ Erlenmeyer flasks. The procedure was repeated 4 more times, resulting in $2 \times 500 \mathrm{~m} \ell$ suspensions.

\section{Stirring duration}

Two media samples were placed in $250 \mathrm{~m} \ell$ beakers, with $100 \mathrm{~m} \ell$ tap water each. One sample was stirred for $30 \mathrm{~s}$ and the other for $60 \mathrm{~s}$, both on high speed and using a large magnetic stirrer (Fig. 3 below). The resultant suspensions were drained off into $2 \times 500 \mathrm{~m} \ell$ Erlenmeyer flasks and the procedure was repeated 4 more times, resulting in $2 \times 500 \mathrm{~m} \ell$ resultant suspensions.

\section{Magnetic stirrer size}

Two media samples were placed in $250 \mathrm{~m} \ell$ beakers, each with 100 $\mathrm{m} \ell$ tap water. Each sample was stirred for $60 \mathrm{~s}$ at high speed, one using a small magnetic stirrer and one using a large magnetic stirrer (see Fig. 3 below for size classifications). The resultant suspensions were drained off into $2 \times 500 \mathrm{~m} \ell$ Erlenmeyer flasks. The procedure was repeated 4 more times, resulting in $2 \times 500 \mathrm{m \ell}$ suspensions.

(a)

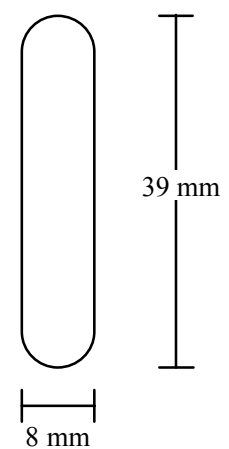

Figure 3

Illustration of size differences of magnetic stirrers used for the refinement of the magnetic stirrer methodology. a = large magnetic stirrer; $b=$ small magnetic stirrer.

\section{Comparison of magnetic stirrer method results}

For each variable tested, i.e. the size of the beaker, the stirring speed, the stirring duration and the magnetic stirrer size, 2 different sizes, speeds, durations and stirrer sizes were used respectively and 3 identical samples were tested for each. Therefore, there were $2 \times 3=6$ tests for each of the 4 variables.

Single-factor ANOVA tests were performed for each method, with the null hypothesis stating that there is no difference in the results due to a change in the variables. The results of these analyses are summarised in Table 3 .

As in the case of the cylinder inversion method, the results from all 4 tests were found to comply with the null hypothesis and, therefore, comparisons of the c.o.v. results were necessary to select which method was favoured.
TABLE 3

Its for $\mathbf{8}$ magnetic stirrer methodologies

\begin{tabular}{|c|c|c|c|c|c|} 
& Mean & $\begin{array}{c}\text { Std. } \\
\text { deviation }\end{array}$ & c.o.v. & F value & $\begin{array}{c}\boldsymbol{F}_{\text {crit }} @ \\
\mathbf{\alpha = 0 . 0 1}\end{array}$ \\
\hline $250 \mathrm{~m} \ell$ & 1476.5 & 139.3 & $\begin{array}{c}9.4 \\
10.8\end{array}$ & 0.1 & 98.50 \\
$500 \mathrm{~m} \ell$ & 1431.0 & 154.1 & 13.2 & & \\
\hline Slow & 1110.5 & 103.9 & 9.4 & 0.3 & \\
Fast & 1183.5 & 156.3 & 13.2 & \\
\hline $30 \mathrm{~s}$ & 799.5 & 101.1 & 12.6 & 24.2 & \\
$60 \mathrm{~s}$ & 1230.5 & 71.4 & 5.8 & & \\
\hline Small & 1297.0 & 14.1 & 1.1 & 16.7 & \\
Large & 1434.0 & 45.3 & 3.2 & & \\
\hline
\end{tabular}

Comparing the c.o.v. values for the beaker size tests, there is very little difference between the 2 values. However, the $250 \mathrm{ml}$ beaker was selected for the final method as it had the lower c.o.v. value.

When comparing the results from the stirring speed tests, the c.o.v. values for the 2 were found to be very similar and, once again, the test with the lower c.o.v. value, namely the slow stirring speed, was chosen for the final method.

At the $a=0.01$ level of significance there was no difference between the results of the stirring duration tests. However, at the $\mathrm{a}=0.05$ level of significance $\left(F_{0.05}=18.5\right)$, there is a difference and the null hypothesis is rejected. The c.o.v. values also supported the statistics, with the c.o.v. value of the 30 s tests being more than double that of the $60 \mathrm{~s}$ tests. Therefore, a 60 s stirring duration was selected for the final method.

The c.o.v. values for the stirrer size methods were both very low and, therefore, any stirrer size could be selected. However, the mean value for the large stirrer tests was closer to the mean values for the beaker size methods, which in turn showed little variation. In terms of practical considerations, the large magnetic stirrer is also easier to handle and more difficult to lose or misplace. Therefore, the large stirrer size was chosen for the final method.

Therefore, the optimal magnetic stirrer method would make use of a $250 \mathrm{~m} \ell$ beaker, with the sample stirred at a slow speed for $60 \mathrm{~s}$, using a large magnetic stirrer.

\section{Comparison of the cylinder inversion method with the magnetic stirrer method}

In taking the mean values obtained from each set of refinement tests, it can be seen (Table 4 below) that the magnetic stirrer method is more effective in removing the solids deposited on the filter media than the cylinder inversion method. However, not all laboratories may have the equipment required for this method readily available and, therefore, the cylinder inversion method could be used in such cases.

\section{Characterising the filter grain residue}

In order to determine the nature of the solids removed during the preceding tests, a number of simple tests were attempted. The basic premise was that the total mass of solids removed from the grains (measured as suspended solids (SS) in the standard way) could be 


\begin{tabular}{|l|c|c|}
\hline \multicolumn{3}{|c|}{ TABLE 4 } \\
\multicolumn{2}{|c|}{$\begin{array}{c}\text { Comparison of turbidity for 2 methodologies } \\
\text { used to measure flocculation retention }\end{array}$} \\
\hline Method used & $\begin{array}{c}\text { Mean } \\
\text { turbidity (NTU) }\end{array}$ & $\begin{array}{c}\text { Difference in } \\
\text { turbidity (\%) }\end{array}$ \\
\hline $\begin{array}{l}\text { Cylinder inversion } \\
\text { Magnetic stirrer }\end{array}$ & 767 & 38 \\
\hline
\end{tabular}

\begin{tabular}{|l|c|c|c|}
\hline \multicolumn{4}{|c|}{ TABLE 5 } \\
\hline & soluble & non-soluble & Total \\
\hline Volatile & $\begin{array}{c}\text { Unknown } \\
\text { Sunpended solids composition matrix }\end{array}$ & $\begin{array}{c}\text { Unknown } \\
\text { B }-\boldsymbol{D}\end{array}$ & $\begin{array}{c}\text { Unknown } \\
\boldsymbol{A}-\boldsymbol{C}\end{array}$ \\
\hline Non-volatile & $\begin{array}{c}\text { Unknown } \\
\boldsymbol{C}-\boldsymbol{D}\end{array}$ & $\begin{array}{c}\text { Known (D) } \\
\text { Eq. (7) }\end{array}$ & $\begin{array}{c}\text { Known (C) } \\
\text { Eq.(6) }\end{array}$ \\
\hline Total & $\begin{array}{c}\text { Unknown } \\
\boldsymbol{A}-\boldsymbol{B}\end{array}$ & $\begin{array}{c}\text { Known (B) } \\
\text { Eq.( 5) }\end{array}$ & $\begin{array}{c}\text { Known (A) } \\
\text { Eq.(4) }\end{array}$ \\
\hline
\end{tabular}

quantitatively separated on the grounds of acid solubility as well as volatility at $550^{\circ} \mathrm{C}$. In this way, the total solids mass could be split into 4 fractions: Non-volatile and non-soluble, non-volatile and soluble, volatile and non-soluble, and volatile and soluble. A number of brief descriptions of these tests follow.

\section{Total suspended solids (TSS)}

A volume of $20 \mathrm{~m} \ell$ to $30 \mathrm{~m} \ell$ of the water sample was drawn off whilst vigorously stirred to prevent settling of the solids, and then filtered through a clean, weighed Millipore glass-fibre prefilter, using Millipore filtration apparatus. Total suspended solids (in $\mathrm{mg} / \ell$ ) is then determined using Standard Methods (1985) procedure 209C and Eq. (4) below:

$$
\mathrm{mg} \text { Total solids } \ell=\frac{(A-B) \times 1000}{\text { Sample volume }(\mathrm{m} \ell)}
$$

where $\mathrm{A}=$ mass of watchglass and filter with dried residue $(\mathrm{mg})$

$$
\mathrm{B}=\text { mass of clean filter }(\mathrm{mg})+\text { mass of watchglass }(\mathrm{mg})
$$

\section{Non-soluble SS}

"Non-soluble solids" is the term applied to the residue of total, suspended, or dissolved solids that remains after treatment with an acid solution.

A $32 \%$ dilution of hydrochloric acid $(\mathrm{HCl})$ was further diluted by $20 \%$, i.e. $25 \mathrm{m \ell}$ of $32 \% \mathrm{HCl}$ is mixed for a minimum of 1 minute with $100 \mathrm{~m} \ell$ water, and $10 \mathrm{~m} \ell$ of this acid was mixed with $100 \mathrm{~m} \ell$ of the resultant suspension. The same procedure as used for the TSS determination is then used to determine the total non-soluble solids (in $\mathrm{mg} / \ell$ ) for the sample, together with Eq. (5) below:

$$
\begin{aligned}
& \text { mg Non-soluble solids } / \ell=\frac{(\mathrm{A}-\mathrm{B}) \times 1000}{\text { Sample volume }(\mathrm{m} \ell)} \\
& \text { where } \mathrm{A}=\text { mass of watchglass and filter with dried acid residue }(\mathrm{mg}) \\
& \qquad \mathrm{B}=\text { mass of clean filter }(\mathrm{mg})+\text { mass of watchglass }(\mathrm{mg})
\end{aligned}
$$

\section{Non-volatile SS}

"Non-volatile or fixed solids" is the term applied to the residue of total, suspended, or dissolved solids remaining after ignition for a specified time at a specified temperature. The mass loss on ignition is called "volatile solids". However, the determinations of nonvolatile and volatile solids do not distinguish between organic and inorganic matter, as the loss on ignition cannot be confined to organic matter, but also includes losses due to decomposition or volatilisation of some mineral salts (Standard Methods, 1985).

The determination of the total non-volatile solids (in $\mathrm{mg} / \ell$ ) was done using Standard Methods (1985) procedure 209D and Eq. (6) below:

$$
\operatorname{mg} \text { Non-volatile solids } / \ell=\frac{(\mathrm{A}-\mathrm{B}) \times 1000}{\text { Sample volume }(\mathrm{m} \ell)}
$$

where $\mathrm{A}=$ mass of watchglass and filter with dried residue before ignition $(\mathrm{mg})$

$$
\mathrm{B}=\text { mass of watchglass and filter with dried residue after ignition }(\mathrm{mg})
$$

This same procedure was also used to determine non-volatile, nonsoluble solids using the acid-sample residue filters and Eq. (7) below:

$$
m g \text { Non - volatile non - soluble solids } / \ell=\frac{(A-B) \times 1000}{\text { Sample volume }(m \ell)}
$$

where $\mathrm{A}=$ mass of watchglass and filter with dried acid residue before ignition $(\mathrm{mg})$

$$
\mathrm{B}=\text { mass of watchglass and filter with dried acid residue after ignition }(\mathrm{mg})
$$

The values obtained using Eqs. (4) to (7) can then be placed in a matrix as follows (Table 5) to determine various unknown values:

The components in Table 5 can roughly be interpreted as follows Haarhoff (2002):

- Soluble, non-volatile originates from the carry-over of chemical precipitates.

- Non-soluble, non-volatile corresponds to inorganic particles present in the raw water.

- Non-soluble, volatile bacterial and algal biomass, organic detritus

\section{Comparison of suspended solids results}

\section{Tests performed on filter sand and granular activated} carbon (GAC)

Suspended solids analyses were performed on filter sand and GAC media, using the cylinder inversion method, for both before and after backwash samples. The samples analysed were taken from various filters at various visits to the plant so that some of the samples represented clogged filters (not recently regenerated or washed), some represented regenerated filters (as in the case of the GAC filters) and some represented recently washed filters.

In each case, samples were taken at 4 depths in the media, at 2 locations in the filter, and were evenly spaced through the profile of the filter. These samples were then combined to form a sample that represented the full profile of the filter.

Each analysis was repeated 3 times for each sample and the results were statistically analysed using a $Q$ test at the $90 \%$ confidence level. This was used to determine if any questionable (or outlying) results should be rejected. In each case, the questionable result is rejected with $90 \%$ statistical confidence if the $Q$ value obtained is larger than the $Q_{0.90}$ value (Fritz and Schenk, 1979). 


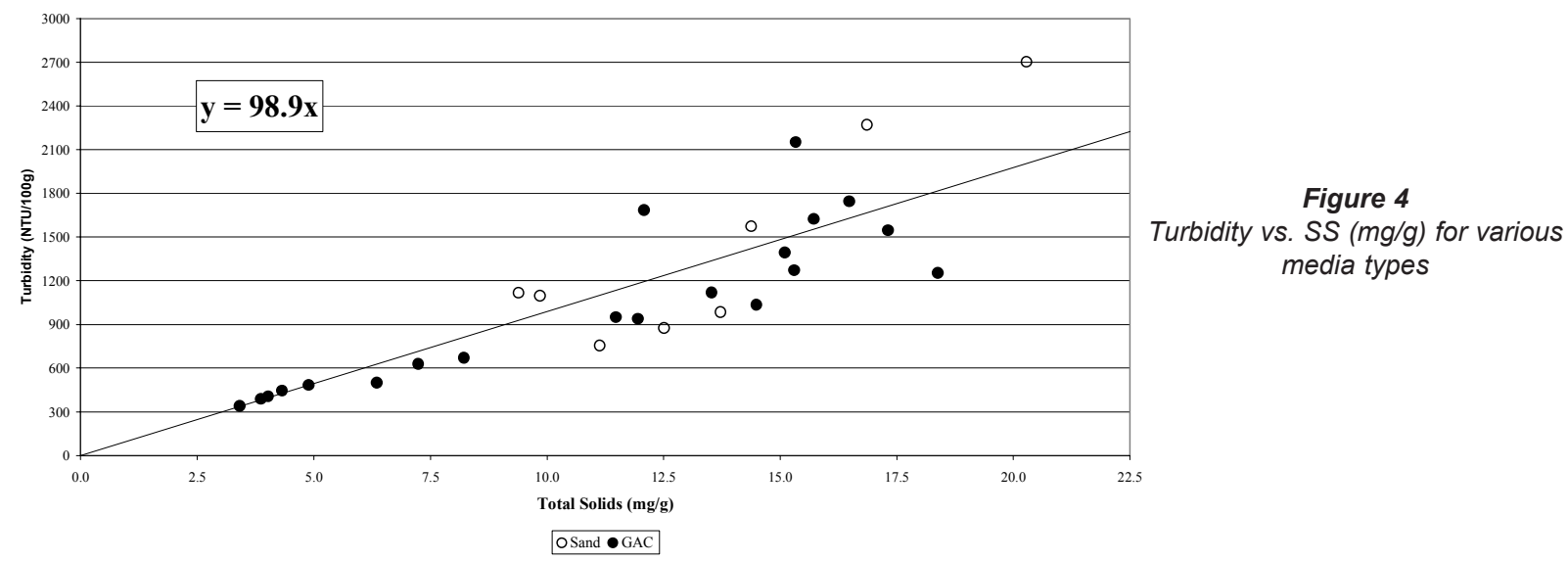

After the questionable results had been discarded, the means of the remaining values were determined and used in Eqs. (4) to (7) and to draw up a matrix of SS composition (as in Table 5 above).

The TSS were measured in $\mathrm{mg} / \ell$ and then converted to $\mathrm{mg} / \mathrm{g}$ using Eq. (8) below and plotted against turbidity (NTU/100g) for comparison of results (see Fig. 4):

mg suspended solids $/ \mathrm{g}=\frac{\text { mg suspended solids } / \ell}{2} \times \frac{1}{\text { weight of media }(\mathrm{g})}$

As can be seen from the graph above, the relationship between turbidity and SS (in $\mathrm{mg} / \mathrm{g}$ ) is very close to turbidity $=100 \times \mathrm{SS}$ $(\mathrm{mg} / \mathrm{g})$.

\section{Discussion and conclusions}

The testing of 3 mechanical agitation and 3 manual agitation methods for the removal of solid deposits from filter media resulted in the choice of the magnetic stirrer method (mechanical agitation) and the cylinder inversion method (manual agitation) and the subsequent refinement of these 2 methods.

The tests performed to refine these 2 methods led to the following 2 procedures to be used for further testing of filter media cleanliness:

\section{Magnetic stirrer method}

1. Obtain a homogenised $60 \mathrm{~m} \ell$ sample (approximately) of filtration media.

2. Weigh the sample and record this value in grams.

3. Perform a moisture content test by weighing a second sample of the sand, both before and after drying. The difference in weight divided by the weight before drying will give the fraction of moisture content of the sample. This value should be used to correct the weight in (2) above.

4. Place the sample in a $250 \mathrm{~m} \ell$ beaker.

5. Add $100 \mathrm{~m} \ell$ clean water to the sample.

6. Using a large magnetic stirrer and magnetic stirring apparatus, continuously stir the media at slow speed for $60 \mathrm{~s}$.

7. Drain off the resultant suspension into a clean, separate $500 \mathrm{~m} \ell$ Erlenmeyer flask, as quickly and accurately as possible.

8. Repeat Steps 5 to 7 an additional 4 times until the Erlenmeyer flask contains a $500 \mathrm{~m} \ell$ suspension.

9. Continuously stir this suspension using additional magnetic stirring apparatus until further analyses can be performed.

\section{Cylinder inversion method}

1. Obtain a homogenised $60 \mathrm{~m} \ell$ sample (approximately) of filtration media.

2. Weigh the sample and record this value in grams.

3. Perform a moisture content test by weighing a second sample of the sand, both before and after drying. The difference in weight divided by the weight before drying will give the fraction of moisture content of the sample. This value should be used to correct the weight in (2) above.

4. Place the sample in a $250 \mathrm{~m} \ell$ measuring cylinder.

5. Add $100 \mathrm{~m} \ell$ clean water to the sample.

6. Seal the end of the measuring cylinder and invert the media 20 times, pausing between inversions to allow the media to settle at the bottom.

7. Drain off the resultant suspension into a clean, separate $500 \mathrm{ml}$ Erlenmeyer flask.

8. Repeat Steps 5 to 7 an additional 4 times until the Erlenmeyer flask contains a $500 \mathrm{~m} \ell$ suspension.

9. Continuously stir this suspension using magnetic stirring apparatus until further analyses can be performed.

The turbidity and composition of the resultant suspensions can then be determined by means of a turbidimeter and SS analyses.

\section{Characterisation of the filter media residue}

The total SS removed from the media sample can be quantitatively separated on the grounds of acid solubility as well as volatility at $550^{\circ} \mathrm{C}$, as follows:

1. Whilst vigorously stirring the resultant suspension, draw off $20 \mathrm{~m} \ell$ to $30 \mathrm{~m} \ell$ and filter through a weighed glass-fibre prefilter, using filtration apparatus.

2. Using Standard Methods (1985) procedure 209C determine the total SS of the sample from this filtrate $(\boldsymbol{A})$.

3. Add $10 \mathrm{~m} \ell 6.4 \%$ hydrochloric acid to $100 \mathrm{~m} \ell$ resultant suspension and stir vigorously.

4. Draw off $20 \mathrm{~m} \ell$ to $30 \mathrm{~m} \ell$ of this acid-water solution, whilst stirring, and filter through a weighed glass-fibre prefilter, using filtration apparatus.

5. Using Standard Methods (1985) procedure 209C determine the total non-soluble solids of the sample from this filtrate $(\boldsymbol{B})$.

6. Using the Standard Methods (1985) procedure 209D and the total SS and total non-soluble SS filtrates, obtained from the above 2 procedures, determine the total non-volatile solids $(\boldsymbol{C})$ and the total non-volatile non-soluble solids $(\boldsymbol{D})$ respectively. 
Using the 4 values determined from the above methods $(\boldsymbol{A}, \boldsymbol{B}, \boldsymbol{C}$ and $\boldsymbol{D})$, determine the unknown values in Table 5, thereby, characterising the filter media residue in terms of 4 values: soluble, nonvolatile; soluble, volatile; non-soluble, non-volatile; and nonsoluble, volatile.

\section{Interpretation of the results}

It is important to realise throughout that the numerical values obtained from the above tests are only relative. Aggressively stirring or inverting a small media sample in the laboratory can strip much more residue from the media than any backwash system possibly can. The total solids stripped from the media by the backwash system will therefore be much less. However, by now being able to perform the tests in a specified, reproducible way, the results obtained from a filter assessment programme can at least be internally compared, a significant improvement on the previous non-specific suggestions in the literature.

\section{Recommendations}

The focus of this paper is to suggest methods for sampling the media, stripping the residue from the media and characterising the filter residue, which was comprehensively reported on. Further work is required to provide guidelines for the interpretation of these results, and to provide typical benchmarks against which such results can be compared.

\section{References}

AMERICAN WATER WORKS ASSOCIATION (AWWA) (2000) Video: Filter Surveillance Techniques for Water Utilities. Catalogue no. 65160. Denver, CO.

CERONIO AD, BASSON ND, KRUGER M, TALJAARD C, BAUMAN CM and HAARHOFF J (2002a) The in-depth evaluation of three filtration facilities. Proc. 8th Bienn. WISA Conf. 19-23 May 2002, ICC, Durban. 10p.

CERONIO AD, HAARHOFF J, BASSON ND, TRAUT D, TITUS G and TIRO P (2002b) The benefits of a systematic filter surveillance programme - A case study from South Africa. Proc. IWA $3^{\text {rd }}$ World Water Congress, 7-12 April 2002, Melbourne, Australia.

FRITZ JS and SCHENK GH (1979) Quantitative Analytical Chemistry (4 $4^{\text {th }}$ edn.). Allyn and Bacon, Inc., Boston, USA.

HAARHOFF J (2002) GAC performance in warmer climates. IWA Workshop on Biological Activated Carbon Filtration. 29-31 May 2002, Delft, Netherlands, 10p.

JOHNSON RA (1994) Chapter 12: Analysis of Variance. In: RA Johnson (ed.) Miller and Freund's Probability and Statistics for Engineers $\left(5^{\text {th }}\right.$ edn.). Prentice-Hall International, Inc., N.J., USA. 387-441.

SPALECK CE (2001) Unpublished undergraduate project investigation report: Die Evaluasie van die Diepbedfilters by Rietvlei Watersuiweringsaanleg. Rand Afrikaans University, Department of Civil and Urban Engineering. November.

STANDARD METHODS (1985) Standard Methods for the Examination of Water and Wastewater (16 $6^{\text {th }}$ edn.). APHA, Washington, DC, USA. 